\title{
Routes to Bioactive Hydrophilic Polymers
}

\author{
Dedicated to the Memory of the late Professor Ichiro Sakurada \\ Clement BAMFord, Ian Middleton, Kadem Al-LAMEe, \\ Jerzy PAPROTNY, and Yoshikatsu SATAKE \\ Institute of Medical and Dental Bioengineering, University of Liverpool, \\ Liverpool L69 $3 B X, U K$
}

(Received January 19, 1987)

\begin{abstract}
The reactions employed for coupling anti-platelet and other drugs to hydroxylic polymers are described. The drugs include the prostaglandin analogue 5-(6-carboxyhexyl)-1-(3cyclohexyl-3-hydroxypropyl) hydantoin (BW 245C) and the phosphodiesterase inhibitors dipyridamole and theophylline. Polymers studied were poly(vinyl alcohol), dextran, and poly(ethylene glycol), and coupling was effected either with the aid of halo-isocyanates or by a two-stage process using carbonyl diimidazole. These novel reaction sequences appear to have wide applications. Some data are presented on the inhibition of platelet aggregation by the free and coupled drugs. KEY WORDS Hydroxylic Polymers / Halo-Isocyanate / Grafting / Bioactive Monomers and Polymers / Carbonyl Diimidazole / Crosslinking /
\end{abstract}

We are honoured by the invitation to contribute to this Memorial Issue of Polymer Journal for Professor Ichiro Sakurada. Among Professor Sakurada's many distinguished contributitions to polymer science was his work on poly(vinyl alcohol). Modifications of this polymer and other hydroxylic macromolecules by grafting and drug attachment are major topics in the present paper.

We are in the process of studying the interactions of blood platelets and drugs chemically bound to polymers, with the object of comparing the activities of free and coupled species which.inhibit platelet aggregation. This approach is yielding improved insight into the mode of drug action, as well as information on the permeability of platelet membranes towards large molecules. Here we discuss various techniques, some novel, for coupling antiplatelet agents to polymers together with a few results obtained by their application.

\section{EXPERIMENTAL}

Poly(vinyl alcohol) (PVA) of molecular weight $125000(88 \%-\mathrm{OH}$ substitution) supplied by B.D.H. Chemicals was dried in vacuum at $60^{\circ} \mathrm{C}$ before use. The same procedure was employed for samples of dextran of average molecular weight 74300 and 9000 obtained from Sigma Chemical Company and poly(ethylene glycol) (PEG) of molecular weight $3300-4000$ and 1540 from B.D.H.

\section{Isocyanation}

PVA and dextran were dissolved in dimethyl sulfoxide (DMSO) (B.D.H. Anala ${ }^{\mathrm{R}}$ grade) which had been dried over a type $4 \mathrm{~A}$ molecular sieve and distilled under diminished pressure; PEG samples were reacted in freshly distilled dichloromethane (B.D.H.). All halo-isocyanates in this work were used as supplied by Aldrich Chemical Company, the exact details of the reaction conditions for individual hydroxylic polymers being set out in Table II. 
Upon completion of the reaction the functionalized polymers were purified by reprecipitation, PVA being precipitated into acetone, dextran into methanol and PEG into diethyl ether.

\section{Grafting}

Grafting of vinyl monomers on to the isocyanated polymers was effected by thermal initiation at $60^{\circ} \mathrm{C}$ with $\mathrm{Mo}(\mathrm{CO})_{6}$ or photochemically by $\operatorname{Re}_{2}(C O)_{10}(\lambda=365 \mathrm{~nm})$. The general experimental arrangements were identical to those employed for grafting on to $N$-halogenated poly(ether-urethanes) and have been described previously. ${ }^{1,2}$ The liquid vinyl monomers employed for grafting were: methyl acrylate (MA), methyl methacrylate (MMA), acrylonitrile (AN) (all ex. B.D.H.), 2-hydroxypropyl acrylate (HPA) (Polysciences), $N, N$ dimethylacrylamide (DMAM) (Fluka) and $N$ vinylpyrrolidone (NVP) (Aldrich). Each monomer was purified by a suitable washing procedure, dependent upon the nature of the added stabilizer, followed by distillation under diminished pressure. NVP was further purified immediately before use as recently outlined by Bamford et al. ${ }^{3}$

\section{Preparation of Bioactive Monomers and Poly- mers}

Dipyridamole Derivatives. Dipyridamole (Sigma) was converted to a polymerizable vinyl monomer by reaction with methacrylic acid (Genzyme-Koch-Light) in the presence of distilled dicyclohexyl carbodiimide (DCC) (Aldrich). 4-dimethylamino pyridine (Aldrich, recrystallized from ethyl acetate) was added as a catalyst and the reaction was allowed to proceed in a mixture of chloroform and dichloromethane $(80: 20, \mathrm{v} / \mathrm{v})$ at ambient temperature for 20 hours. The monomethacrylate ester DIMA (see Section 1.1) was isolated by thin-layer chromatography with ethyl acetate as eluent and was identified ${ }^{4}$ by elemental analysis, infrared (IR), proton NMR and chemical ionization mass spectroscopy.
DIMA was copolymerized with NVP by thermal initiation with azobis(isobutyronitrile) (Aldrich) at $60^{\circ} \mathrm{C}$ in methanol solution. The copolymers produced were isolated and purified by reprecipitation from methanol into diethyl ether-acetone $(80: 20 \mathrm{v} / \mathrm{v})$ mixtures. The contents of dipyridamole in random copolymers of DIMA and in grafts on to hydroxylic polymers were estimated spectrophotometrically from the UV absorption at $i=410 \mathrm{~nm}$.

B.W 245C Derivatives. Procedures similar to the above were employed for the esterification of BW 245C (a generous gift from Dr. N. Whittaker of the Wellcome Research Laboratories) with hydroxy-methacrylates and halo-alcohols, and in subsequent polymerization with NVP, as described in an earlier publication. ${ }^{5} \mathrm{BW} 245 \mathrm{C}$ was also available as a tritiated sample, enabling estimation of the content of the drug in polymeric derivatives to be carried out by liquid scintillation counting.

Theophylline-Direct Coupling to Hydroxylic Polymers. Use of ${ }^{14} \mathrm{C}$-labelled theophylline-7acetic acid enabled the extent of coupling to hydroxylic polymers to be determined by liquid scintillation counting. The ${ }^{14} \mathrm{C}$-labelled acid was prepared by refluxing theophylline (Aldrich) with $1-{ }^{14} \mathrm{C}$-bromoacetic acid (Amersham International) in $0.5 \mathrm{M}$ sodium hydroxide solution for 18 hours. The product was precipitated by neutralization with hydrochloric acid, filtered and purified by double recrystallization from distilled water. The final material had a $\mathrm{mp}\left(268.5^{\circ} \mathrm{C}\right)$ and an IR spectrum identical to those of an unlabelled commercial sample (Fluka). Esterifications were carried out by stirring the ${ }^{14} \mathrm{C}$-theophylline-7acetic acid with carbonyl diimidazole (CDI) (Aldrich, used as supplied) in either DMSO or dichloromethane until no further evolution of $\mathrm{CO}_{2}$ could be detected (approximately 30 minutes) after which the required weight of hydroxylic polymer in solution was added and the reaction allowed to proceed for 20 hours. Purification was again effected by 
reprecipitation in order to remove unreacted theophylline-7-acetic acid. Methanol was the precipitant for PVA and dextran, and a mixture of diethyl ether and methanol $(90: 10 \mathrm{v} / \mathrm{v})$ was used for PEG.

Crosslinking of Hydroxylic Polymers. Crosslinking of PVA or dextran was carried out by mechanical shaking of a solution of the polymer in DMSO with an approximately equal weight of carbonyl diimidazole yielding a network structure within a few hours. Inclusion of appreciable amounts of dipyridamole in the reaction may reduce the gelation time to a few minutes. Formamidebased solvent mixtures were also used with dextran in this reaction ${ }^{6}$ without any dramatic effect on the gelation time. Aggregation. The inhibitory activities of dipyridamole, BW $245 \mathrm{C}$ and their derivatives to-
Measurement of Inhibition of Platelet

wards adenosine diphosphate (ADP)-induced aggregation of sheep platelet-rich-plasma were assessed by conventional Born aggregometry. ${ }^{7}$

\section{RESULTS AND DISCUSSION}

1. Coupling with the Aid of Halo-isocyanates By virtue of their dual functionalities, haloalkyl- and haloacyl-isocyanates are especially useful reagents for coupling macromolecules to other species. The overall strategy involves reacting the isocyanate moiety with a convenient group in the polymer and using the unreacted halogen group in the adduct for subsequent coupling, either by direct reaction or by polymerization procedures. For example, the isocyanation of a hydroxylic polymer with trichloroacetyl isocyanate is represented by reaction 1 .

Isocyanation
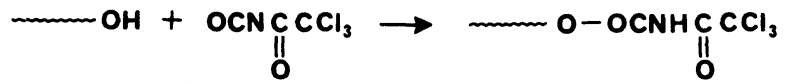

The reactive halogens in the product may be used for co-initiation with a transition metal

carbonyl in grafting a block of any vinyl polymer (reaction 2$)^{8}$

Grafting

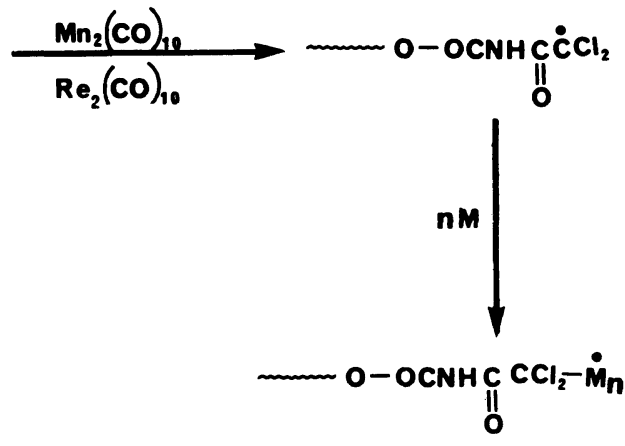

of monochloroalkyl isocyanate followed by direct reaction with ammonia or the amino groups of either a spacer arm or a drug molecule. Further, the technique is not limited to hydroxylic polymers but is also effective with macromolecules possessing $-\mathrm{COOH}$, 
$-\mathrm{CONH}_{2},-\mathrm{CONH}-$, or $-\mathrm{OCONH}-$ groups.

\section{Monomers and Initiators}

In principle, reaction 2 may be used to couple any drug which carries a polymerizable vinyl goup or into which such a group may be introduced. Polymerization or copolymerization of such monomers yields products carrying the drug in side chains. Alternatively, the drug may be functionalized by introduction of halogen-containing groups which are used to coinitiate polymerization with transition metal derivatives as in reaction $2.5,9$ The polymeric products have the drug attached as terminal units in the chains.

We have converted ${ }^{5}$ the prostaglandin analogue BW $245 \mathrm{C}$ (1) into two series of monomethacrylate esters (2), (3), and dipyridamole ((4), $\left.\mathrm{R}^{\prime}=\mathrm{H}\right)$ into the monomethacrylate ester DIMA $\quad\left((4), \quad \mathrm{R}^{\prime}=-\mathrm{OC}-\mathrm{C}\left(\mathrm{CH}_{3}\right)=\mathrm{CH}_{2}\right) .{ }^{4}$ Further, coinitiators were prepared by coupling (1) to 2,2,2-trichloroethanol (5) and 2bromoethanol (6).<smiles>CC[C@@H](O)[C@H]1CCN2C(=O)NC(=O)[C@@H]2CCCC=C=C1C(=O)O</smiles><smiles>[3H][R]O</smiles><smiles>[R]OC(=O)C1=C=CCCC[C@H]2C(=O)NC(=O)N2CC[C@@H]1[C@H](O)CC</smiles>

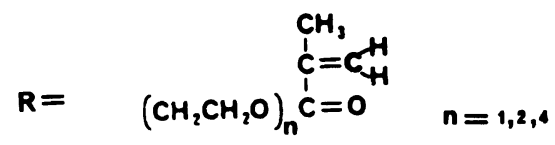

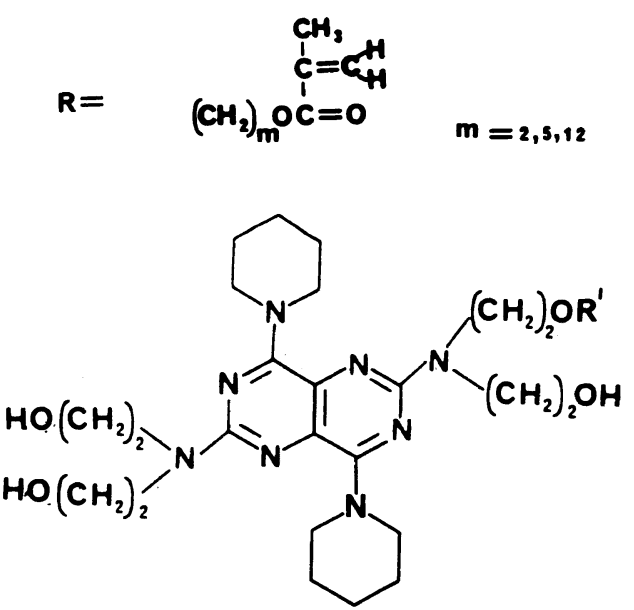

$\mathrm{HOCH}_{2} \mathrm{CCl}_{3}$

$\mathrm{HOCH}_{2} \mathrm{CH}_{2} \mathrm{Br}$

(6)

\section{Bioactivities}

The monomers and initiators prepared from (1) are bioactive, as are their copolymers with NVP. In Figure 1 the activities of (1) bound to polymer chains are expressed as fractions of the activity of the parent. Esters of (1) have about $10 \%$ of the activity of the parent as inhibitors of platelet aggregation, but incorporation of (1) into a polymer chain reduces the activity still further. As a terminal residue, (1) has approximately $1 \%$ of its activity when free; as side-chain units a more dramatic decrease occurs, almost by a

Table I. Activities of dipyridamole and derivatives

\begin{tabular}{lcc}
\hline \multicolumn{1}{c}{ Species } & $\begin{array}{c}\text { Concentration of } \\
\text { dipyridamole for } \\
50 \% \text { inhibition }\end{array}$ & $\begin{array}{c}\text { Relative } \\
\text { activity }\end{array}$ \\
\cline { 2 - 3 } & 100 & 1 \\
\hline Dipyridamole & 250 & 0.8 \\
DIMA & & \\
NVP-DIMA copolymer, & 120 & 1.67 \\
$\begin{array}{l}\text { 9.5\% w/w } \\
\text { dipyridamole }\end{array}$ & & \\
NVP-DIMA copolymer, \\
$\begin{array}{l}20 \% \text { w/w } \\
\text { dipyridamole }\end{array}$ & 12 & 16.7 \\
\hline
\end{tabular}




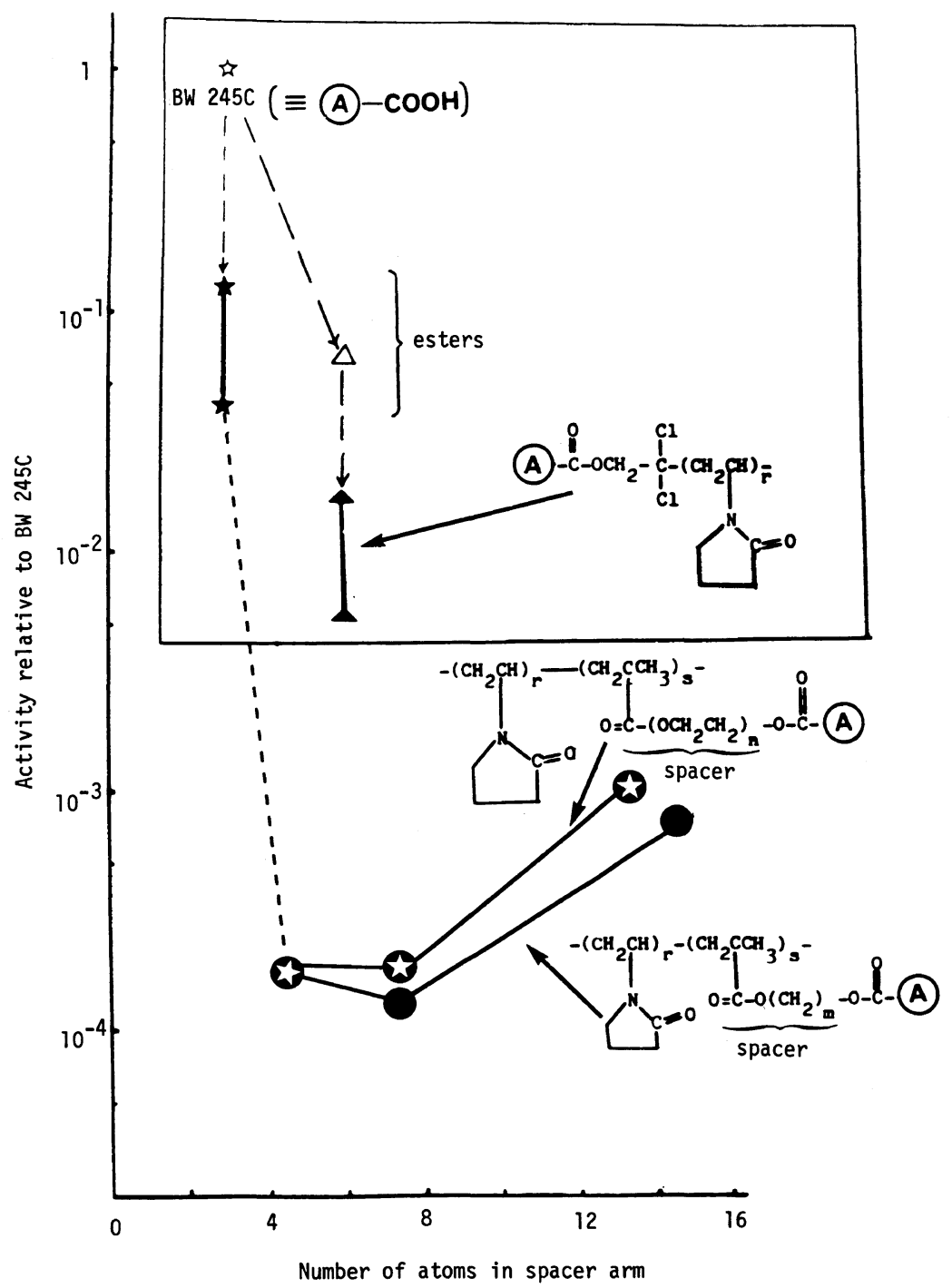

Figure 1. Inhibition of ADP-induced platelet aggregation by BW $245 \mathrm{C}$ and derivatives. Influence of length and hydrophilicity of spacer arm on activity of BW $245 \mathrm{C}$ coupled to $\operatorname{poly}(N$-vinylpyrrolidone $)$.

factor $10^{4}$, but somewhat dependent on the length and hydrophilicity of the spacer arms as shown in Figure 1. In view of the very high inhibitory activity of (1) these polymers are sufficiently active to be of practical interest.

The activities of dipyridamole derivatives are given in Table $I$ relative to that of the parent drug (for $50 \%$ inhibition of platelet aggregation).

Note that dipyridamole becomes more ac- tive when coupled to the polymer as side chains, in marked contrast to the behavior of BW 245C (Figure 1). We believe that these differences arise from contrasting steric requirements of the drug-receptor interactions.

\section{Isocyanation of Hydroxylic Polymers}

Poly(vinyl alcohol), Dextran, and Poly(ethylene glycol). Poly(vinyl alcohol) and dextran may be conveniently isocyanated in 
Table II. Isocyanation of poly(vinyl alcohol), dextran ( $\overline{\mathrm{M}} 74000)$ and poly(ethylene glycol) $(\overline{\mathrm{M}} 3300-4000)$ at $25^{\circ} \mathrm{C}$

\begin{tabular}{|c|c|c|c|c|c|}
\hline Polymer & & Volume of solution & Isocyanate & $\begin{array}{l}\text { Reaction } \\
\text { time }\end{array}$ & $\begin{array}{c}\mathrm{Cl} \\
\text { content }\end{array}$ \\
\hline wt, $g$ & & $\mathrm{ml}$ & vol, ml & $\mathrm{h}$ & $\%$ \\
\hline Poly(vinyl alcohol) (2) & DMSO & 30 & $\mathrm{Cl}_{3} \mathrm{CCO} \mathrm{NCO}$ & 20 & 1.46 \\
\hline Poly(vinyl alcohol) (2) & DMSO & 30 & $\begin{array}{c}\mathrm{ClCH}_{2} \mathrm{CH}_{2} \mathrm{NCO} \\
(0.7)\end{array}$ & 20 & 2.43 \\
\hline Poly(vinyl alcohol) (2) & DMSO & 15 & $\underset{\text { (1) }}{\mathrm{ClCH}_{2} \mathrm{CO}} \mathrm{NCO}$ & 20 & 0.20 \\
\hline Dextran (1.7) & DMSO & 11 & $\underset{\text { (2) }}{\mathrm{Cl}_{3} \mathrm{CCO} \mathrm{NCO}}$ & 1 & 0.68 \\
\hline Poly(ethylene glycol) (5) & $\mathrm{CH}_{2} \mathrm{Cl}_{2}$ & 13 & $\mathrm{Cl}_{3} \mathrm{C} \mathrm{CO} \mathrm{NCO}$ & 1 & 6.0 \\
\hline
\end{tabular}

Table III. Photografting to isocyanated hydroxylic polymers in DMSO solution at $25^{\circ} \mathrm{C}$

\begin{tabular}{|c|c|c|c|c|c|c|}
\hline \multicolumn{2}{|c|}{ Isocyanated polymer } & \multicolumn{2}{|c|}{ Monomer grafted } & \multirow{2}{*}{$\frac{10^{3}\left[\operatorname{Re}_{2}(\mathrm{CO})_{10}\right]}{\mathrm{mol} \mathrm{dm}^{-3}}$} & \multirow{2}{*}{$\frac{\begin{array}{c}\text { Reaction } \\
\text { time }\end{array}}{\mathrm{h}}$} & \multirow{2}{*}{$\begin{array}{c}\text { Weight } \\
\text { increase }\end{array}$} \\
\hline Type & $\begin{array}{l}\text { Concn/ } \\
\mathrm{g} \mathrm{dm}^{-3}\end{array}$ & Type & $\begin{array}{l}\text { Concn/ } \\
\mathrm{moldm}^{-3}\end{array}$ & & & \\
\hline \multirow{5}{*}{$\mathrm{PVA} / \mathrm{Cl}_{3} \mathrm{C} \mathrm{CONCO}$} & 30 & AN & 5.04 & 2.29 & 0.25 & 11.1 \\
\hline & 33.3 & MMA & 1.56 & 1.48 & 4 & 130 \\
\hline & 33.3 & HPA & 1.28 & 1.22 & 3.5 & 267 \\
\hline & 32.3 & MA & 2.56 & 1.81 & 2 & 576 \\
\hline & 32.3 & DMAM & 2.32 & 1.74 & 2 & 570 \\
\hline a) & 62 & DIMA/NVP & $0.05 / 1.01$ & 20.0 & 5 & 16.5 \\
\hline \multirow{2}{*}{$\mathrm{PVA} / \mathrm{ClCH}_{2} \mathrm{CH}_{2} \mathrm{NCO}$} & 30.7 & AN & 3.50 & 1.17 & 5 & 166 \\
\hline & 30.7 & MMA & 2.16 & 1.43 & 5.5 & 197 \\
\hline \multirow{2}{*}{$\mathrm{PVA} / \mathrm{ClCH}_{2} \mathrm{CO} \mathrm{NCO}$} & 30.7 & AN & 3.4 & 1.67 & 1.5 & 700 \\
\hline & 30.7 & MMA & 2.09 & 1.67 & 1.5 & 900 \\
\hline \multirow[t]{3}{*}{ Dextran $/ \mathrm{Cl}_{3} \mathrm{C} \mathrm{CO} \mathrm{NCO}$} & 17 & AN & 5.0 & 1.58 & 1.5 & 800 \\
\hline & 15 & HPA & 3.8 & 1.62 & 4 & 2110 \\
\hline & 12.5 & MMA & 2.3 & 1.18 & 5 & 1180 \\
\hline $\mathrm{PEG} / \mathrm{Cl}_{3} \mathrm{C} \mathrm{CO} \mathrm{NCO}$ & 55 & MMA & 3.1 & 2.12 & 4 & 270 \\
\hline a) $\mathrm{Cl}_{3} \mathrm{C} \mathrm{CO} \mathrm{NCO}$ & 100 & DIMA & 0.03 & 19.0 & 5 & 2.6 \\
\hline a) $\mathrm{PEG} / \mathrm{Cl}_{3} \mathrm{C} \mathrm{CO} \mathrm{NCO}$ & 140 & DIMA/NVP & $0.05 / 1.01$ & 20.0 & 6 & 18.5 \\
\hline $\mathrm{PEG} / \mathrm{Cl}_{3} \mathrm{C} \mathrm{NCO}$ & 6.0 & $\mathrm{AN}$ & 6.1 & 1.84 & 3 & 167 \\
\hline
\end{tabular}

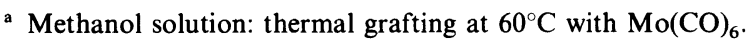

DMSO solution under conditions shown in Table II. Poly(ethylene glycol) is soluble in a variety of liquids and we have found methylene chloride suitable for the present purpose. The proportions of polymer and halo- isocyanate and the reaction time are determined by the degree of isocyanation desired.

\subsection{Grafting}

Photografting of vinyl monomers to the 


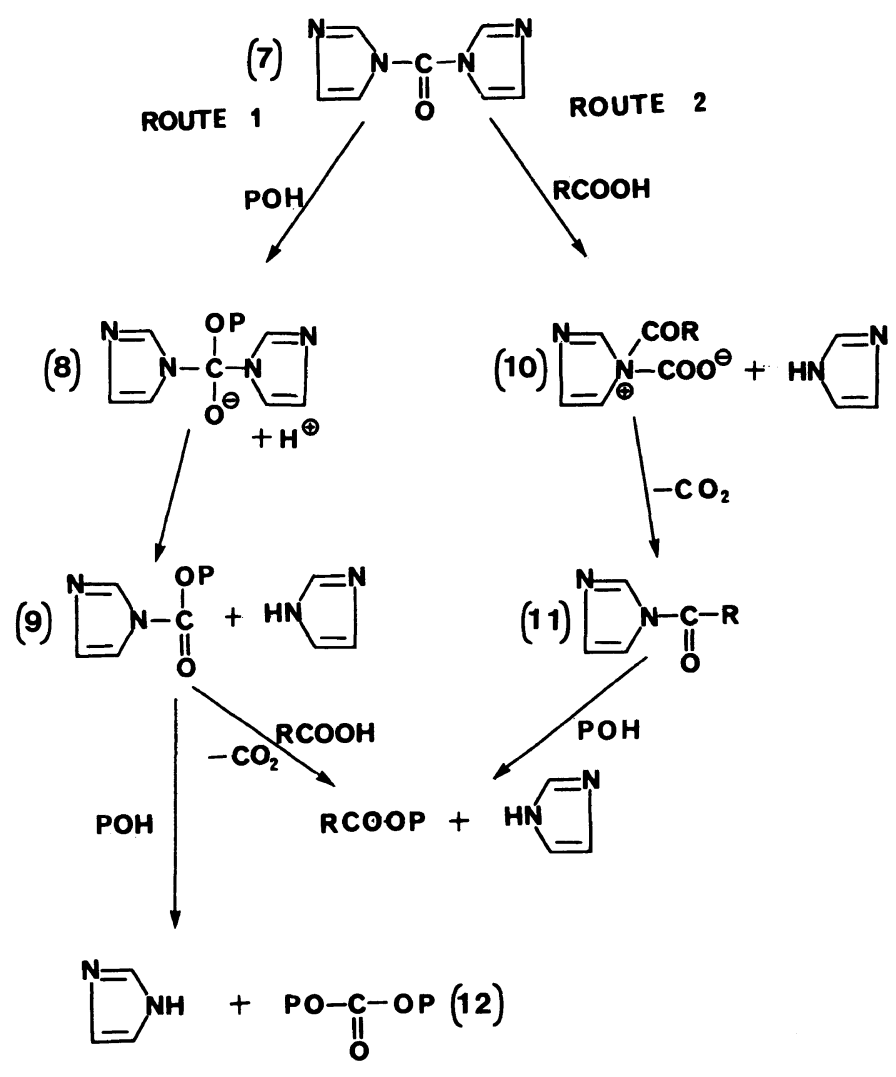

Scheme 1.

isocyanated polymers according to reaction 2 was effected with the aid of rhenium carbonyl with results shown in Table III.

The bioactivities of grafts containing dipyridamole made in this way are currently under examination.

\section{Direct Coupling with the Aid of Carbonyl} Diimidazole (CDI)

We have recently discussed ${ }^{6}$ the merits of CDI (7) as a coupling agent for use with polymeric species. An outstanding advantage possessed by CDI over carbodiimides is that it can be used with DMSO, which is often a good solvent for hydroxylic polymers.

It is known ${ }^{10,11}$ that DMSO brings about the facile oxidation of alcohols in the presence of DCC, being reduced in the process to dimethyl sulphide. Two routes for coupling carboxylic acids to hydroxylic polymers with the aid of CDI may be distinguished and are set out in Scheme 1 ( $\mathrm{P}=$ polymer chain). Both routes 1 and 2 yield the ester RCOOP via intermediates (8), (9) and (10), (11), respectively. Route 1 has the disadvantage of forming the carbonate species (12); with lowmolecular-weight reactants this may be removed by conventional purification, but formation of (12) is very troublesome with polymeric species, since it introduces crosslinking. However, carbonate formation is useful if it is desired to crosslink the initial hydroxylic polymer. Examples of this are given later.

Route 2 is conveniently carried out as a two-stage process ${ }^{6}$ and we have used it for coupling theophylline ((13), $\mathrm{R}=\mathrm{H})$, an inhib- 
Table IV. Coupling of theophylline acetic acid (TAA) to hydroxylic polymers with CDI

\begin{tabular}{|c|c|c|c|c|c|c|}
\hline \multirow{2}{*}{$\frac{\text { Polymer }}{\mathrm{mol} \cdot \mathrm{wt}}$} & \multirow{2}{*}{$\begin{array}{c}\begin{array}{c}\text { Weight of } \\
\text { polymer }\end{array} \\
\mathrm{g}\end{array}$} & \multirow{2}{*}{$\begin{array}{c}\text { Solvent } \\
\text { vol } \mathrm{ml}^{-1}\end{array}$} & \multirow{2}{*}{$\begin{array}{c}\text { Weight of } \\
\text { TAA } \\
\mathrm{g}\end{array}$} & \multirow{2}{*}{$\frac{\begin{array}{c}\text { Weight of } \\
\text { CDI }\end{array}}{\mathrm{g}}$} & \multicolumn{2}{|c|}{$\%$ TAA (w/w) } \\
\hline & & & & & In polymer & Coupled \\
\hline Dextran (74000) & 1.0 & DMSO (10) & 0.165 & 0.12 & 6.7 & 41.2 \\
\hline Dextran $(9000)$ & 1.0 & DMSO (10) & 0.15 & 0.14 & 5.0 & 33.3 \\
\hline PEG $(3300-4000)$ & 2.0 & $\mathrm{CH}_{2} \mathrm{Cl}_{2}$ (12) & 0.26 & 0.18 & 7.9 & 60.5 \\
\hline PEG (1540) & 3.0 & $\mathrm{CH}_{2} \mathrm{Cl}_{2}(12)$ & 0.95 & 0.65 & 10.2 & 32.4 \\
\hline PVA (125000) & 2.0 & DMSO (20) & 0.72 & 0.49 & 6.9 & 17.3 \\
\hline
\end{tabular}

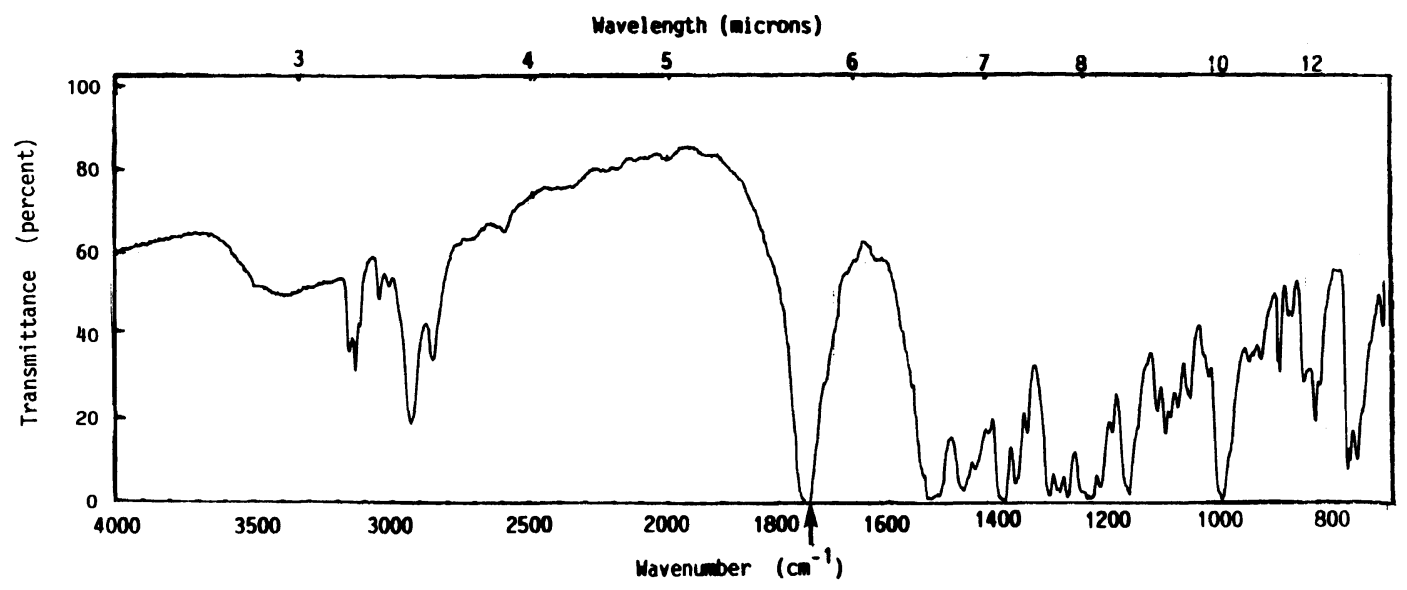

Figure 2. IR spectrum of poly(vinyl alcohol) crosslinked with dipyridamole. Carbonate absorption, $\uparrow$.

itor of phosphodiesterase, via an ester linkage. For this purpose theophylline was converted to theophylline-7-acetic acid ((13) $\mathrm{R}=$ $\left.\mathrm{CH}_{2} \mathrm{COOH}\right)$. Some results are given in Table IV.<smiles></smiles>

Akashi and co-workers ${ }^{12}$ have converted theophylline into $N$-acryloyl and $N$-methacryloyl derivatives by reaction with the corresponding acid chlorides; the resulting monomers were homopolymerized or copolymerized with methyl acrylate. This procedure leads to a very labile attachment of theophyl- line, the half-life in aqueous media in some cases being as short as one minute; in fact these derivatives structurally resemble the acylimidazole species (11) in route 2 of Scheme 1.

When a hydroxylic polymer is treated with CDI in solution in the absence of a carboxylic acid, the reactions of route 1 lead to formation of carbonate crosslinks and to ultimate gelation. We have observed this process with PVA and dextran in DMSO and formamide soluions, respectively. The IR of the crosslinked polymer, thoroughly dried in vacuum at $60^{\circ} \mathrm{C}$, shows strong absorption at $1760 \mathrm{~cm}^{-1}$, a frequency which is characteristic of alkyl carbonates (Figure 2). In the presence of dipyridamole ((4), $\left.R^{\prime}=H\right)$ the hydroxyl groups of the latter react so that a network containing the drug is formed. 


\section{REFERENCES}

1. C. H. Bamford and I. P. Middleton, Eur. Polym. J., 19, 1027 (1983).

2. C. H. Bamford and I. P. Middleton, "Plenary and Invited Lectures," Macro 83, Bucharest, Rumania, $p$ 168.

3. C. H. Bamford, E. Schofield, and D. J. Michael, Polymer, 26, 945 (1985).

4. C. H. Bamford, I. P. Middleton, and K. G. AlLamee, Biochim. Biophys. Acta, in course of publication.

5. C. H. Bamford, I. P. Middleton, Y. Satake, and K. G. Al-Lamee, "Advances in Polymer Synthesis," B. M. Culbertson and J. E. McGrath, Ed., Plenum Press Publishers, New York, 1985, p 291.

6. C. H. Bamford, I. P. Middleton, and K. G. AlLamee, Polymer, 27, 1981 (1986).
7. C. H. Bamford, I. P. Middleton, and K. G. AlLamee, Biochim. Biophys. Acta, 886, 109 (1986).

8. C. H. Bamford, "New Trends in the Photochemistry of Polymers," N. S. Allen and J. F. Rabek Ed., Elsevier Applied Science Publishers, London, 1985, p 125.

9. C. H. Bamford, I. P. Middleton, Y. Satake, and K. G. Al-Lamee, in "Blood Compatible Materials and their Testing," S. Dawids and A. Bantjes, Ed., Martinus Nyhoff Publishers, Dordrecht, Netherlands, 1986, p 159.

10. K. E. Plitzner and J. G. Moffatt, J. Am. Chem. Soc., 87, 5661 (1965).

11. A. H. Fensau and J. G. Moffatt, J. Am. Chem. Soc., 88, 1762 (1966).

12. M. Akashi, Y. Tanaka, T. Miyazakai, and N. Miyauchi, "Macromolecular Preprints," Macromolecules 86 Conference, Oxford, p 81. 